\title{
Radiobiological effects of tritiated water short-term exposure on V79 clonogenic cell survival
}

Siragusa, Mattia; Fredericia, Nina Pil Møntegaard; Jensen, Mikael; Groesser, Torsten

Published in:

International Journal of Radiation Biology

Link to article, DOI:

10.1080/09553002.2018.1419301

Publication date:

2018

Document Version

Publisher's PDF, also known as Version of record

Link back to DTU Orbit

Citation (APA):

Siragusa, M., Fredericia, N. P. M., Jensen, M., \& Groesser, T. (2018). Radiobiological effects of tritiated water short-term exposure on V79 clonogenic cell survival. International Journal of Radiation Biology, 94(2), 57-165. https://doi.org/10.1080/09553002.2018.1419301

\section{General rights}

Copyright and moral rights for the publications made accessible in the public portal are retained by the authors and/or other copyright owners and it is a condition of accessing publications that users recognise and abide by the legal requirements associated with these rights.

- Users may download and print one copy of any publication from the public portal for the purpose of private study or research.

- You may not further distribute the material or use it for any profit-making activity or commercial gain

- You may freely distribute the URL identifying the publication in the public portal 


\section{Radiobiological effects of tritiated water short- term exposure on V79 clonogenic cell survival}

\section{Mattia Siragusa, Pil M. Fredericia, Mikael Jensen \& Torsten Groesser}

To cite this article: Mattia Siragusa, Pil M. Fredericia, Mikael Jensen \& Torsten Groesser (2018) Radiobiological effects of tritiated water short-term exposure on V79 clonogenic cell survival, International Journal of Radiation Biology, 94:2, 157-165, DOI: 10.1080/09553002.2018.1419301

To link to this article: https://doi.org/10.1080/09553002.2018.1419301
(c) 2018 Mattia Siragusa, Pil M. Fredericia, Mikael Jensen and Torsten Groesser. Published with license by Informa UK Limited, trading as Taylor \& Francis Group.

Accepted author version posted online: 03
Jan 2018.
Published online: 11 Jan 2018.
Submit your article to this journal

ЏIII Article views: 416

$$
\text { View Crossmark data }
$$




\title{
Radiobiological effects of tritiated water short-term exposure on V79 clonogenic cell survival
}

\author{
Mattia Siragusa*, Pil M. Fredericia*, Mikael Jensen and Torsten Groesser
}

The Hevesy Laboratory at DTU Nutech, Technical University of Denmark (DTU), Copenhagen, Denmark

ABSTRACT

Purpose: We set out to improve the accuracy of absorbed dose calculations for in vitro measurements of the relative biological effectiveness (RBE) of tritiated water (HTO) for the clonogenic cell survival assay, also considering the influence of the end-of-track linear energy transfer (LET) of low-energy electrons.

Materials and methods: The COmputation Of Local Electron Release (COOLER) program was adopted to investigate the cell geometry and the tritium full beta-decay spectrum impact on the S-values and subsequently on the RBE of HTO for clonogenic cell survival at similar high dose rates (HDR).

Results: S-values for cells growing in suspension are usually comparable to those for adherent cells. RBEs calculated at the $10 \%$ survival fraction through the use of the average energy are almost similar to those obtained with the beta-spectrum. For adherent cells, an RBE of 1.6 was found when HTO cell survival curves were compared to acute $\gamma$-ray exposures. Irrespective of the geometrical configuration, the RBE was 2.0 when the comparison was made with similar dose rates.

Conclusions: These results underline the importance of irradiating at equal dose rates and cell culture conditions when measuring in vitro RBE-values.
ARTICLE HISTORY

Received 10 August 2017

Revised 1 December 2017

Accepted 11 December 2017

\section{KEYWORDS}

RBE; HTO; S-values; COOLER; Auger electrons

\section{Introduction}

Tritium $\left({ }^{3} \mathrm{H}\right)$ is a radioactive isotope of hydrogen and decays solely by $\beta^{-}$decay to ${ }^{3} \mathrm{He}$ through emission of an electron $(\beta$-ray) with a well-known spectral distribution and a maximum energy of $18.6 \mathrm{keV}$. The co-emitted electron antineutrino can be safely disregarded in this dosimetric context. The range of the tritium beta electrons at $18.6 \mathrm{keV}$ is approximately $6 \mu \mathrm{m}$ in water (Carsten 1979), which is fairly short when compared to the average size of a mammalian cell diameter (approximately 10-20 $\mu \mathrm{m}$ ). Its characteristics are well described in the literature and summarized in Table 1. Tritium has a half-life of 12.33 years and has both natural origins (cosmic ray interactions with the atmosphere) and artificial sources (reactors and accelerators, nuclear weapons testing). It is present in the human environment and deserves some attention for radiation protection reasons, especially as it has a rapid biological distribution both as tritiated water (HTO) and as organic bound tritium. The release of HTO from nuclear power plants into the underground and eventually drinking water is considered a common source of radiation exposure to the general public (Carsten 1979; Vri and Binet 1984; Le Guen 2009).

In order to assess the biological damage of HTO, accurate calculations of the absorbed dose are necessary and a relative biological effectiveness (RBE) different from unity needs also to be considered. This is, in particular, true for chronic exposures to HTO; partly due to the dynamic incorporation of tritium in biomolecules or DNA precursors. The incorporation can lead to a permanent exposure of the DNA up to the end of the lifespan of cells, and to some extent to progenitor cells (Harrison et al. 2002). Many studies have examined the radiation effect of tritium in cell cultures as well as in vivo models (Little and Lambert 2008; Little and Wakeford 2008). In many cases, these studies measured the radio-biological effect at low dose rates to mimic the chronic exposures in humans. Tritium is able to diffuse throughout the human body like water within hours and the exposure is assumed to be homogenous (Pinson and Langham 1957). The tritium atom is considered to be biologically mobile in the sense that it rapidly replaces the hydrogen atoms of biomolecules, depending on the accessibility (Diabaté and Strack 1993; Goodhead 2002).

In this study, we have been interested in the RBE of HTO without the confounding effect of direct DNA incorporation, both to provide new fundamental knowledge about the biological action of tritium, but also as an experimental model for assessing the RBE of low energy electron emissions in the

CONTACT Torsten Groesser togro@dtu.dk www.dtu.dk 0 The Hevesy Laboratory, Center for Nuclear Technologies, Technical University of Denmark, Building 202, Frederiksborgvej 399, 4000 Roskilde, Denmark

*Scholar in Training.

(C) 2018 Mattia Siragusa, Pil M. Fredericia, Mikael Jensen and Torsten Groesser. Published with license by Informa UK Limited, trading as Taylor \& Francis Group.

This is an Open Access article distributed under the terms of the Creative Commons Attribution-NonCommercial-NoDerivatives License (http://creativecommons.org/Licenses/by-nc-nd/ 4.0/), which permits non-commercial re-use, distribution, and reproduction in any medium, provided the original work is properly cited, and is not altered, transformed, or built upon in any way. 
Table 1. Characteristics of tritium.

\begin{tabular}{llll}
\hline Energy & Max. & $18.6 \mathrm{keV}$ & Carsten (1979) \\
& Average & $5.7 \mathrm{keV}$ & \\
Range in water & Max. & $6 \mu \mathrm{m}$ & \\
& Average & $0.56 \mu \mathrm{m}$ & Lucas and Unterweger (2000) \\
Half-life & & 12.33 years & NCRP Report (1979) \\
LET & Initial LET & $3.5 \mathrm{keV} / \mu \mathrm{m}$ & $5.5 \mathrm{keV} / \mu \mathrm{m}$ \\
\end{tabular}

cell nucleus. This is of special interest in damage assessments of the intracellular Auger electron emitters, which are often indicated as very good candidates for internal radiotherapy (Kassis 2004). The tritium beta energies are in the same range as many Auger electrons, but this model avoids the complications of multiple electron emissions with a strong spatial and temporal correlation. Thus we hope to isolate the two contributing factors to the enhanced radiological toxicity of intracellular Auger-emitters: the multiplicity effect from the disproportionate high influence of the end-of-track linear energy transfer (LET) of low energy electrons.

We used rather high intra-cellular dose rates provided by a high HTO concentration in the cell culture medium, to reduce the exposure time and therefore minimize tritium incorporation into the DNA. This reduced the uncertainties in the absorbed dose calculations (Harrison et al. 2002). Furthermore, we have carefully matched the dose rates of the external ${ }^{60} \mathrm{Co}$ gamma-ray exposures (the reference exposures) to that obtained with the internal HTO exposures, hereby preventing underestimation of the biological effects due to the dose rate effect. It is widely accepted that reducing the dose rate will lower the biological effect for the same given radiation dose (Hall et al. 1967). This is due to the fact that the cells have more time to repair the induced DNA damage in the protracted (low dose rate) case compared to the acute exposure.

For the calculation of the absorbed dose from HTO to our cell culture model, we have used the formalism of cellular Svalues as defined by the Medical Internal Radiation Dose (MIRD) committee (Goddu et al. 1997). S-values represent the absorbed dose to a target region (in our case the cell nucleus) per decay in a source region (e.g. the nucleus, the cytoplasm, or the cell culture medium). In this work, they are calculated using a dedicated extension of the recently published COmputation Of Local Electron Release (COOLER) program (Siragusa et al. 2017). COOLER relies on the mathematical convolution of two terms: one related to the position of electron sources (the sites where tritium decays), the other to the density of deposited energy as a function of radial distance from a point source.

We decided to measure the clonogenic cell survival in Chinese hamster V79 lung fibroblasts because of their ability to grow as attached monolayers as well as in a suspension culture. V79 cells were also chosen for their adoption as a radiobiological model in the COOLER program. This has allowed us to study the effect of HTO exposure under different cell growth conditions. In COOLER, two realistic geometrical models for V79 cells are implemented for different cell culture conditions, namely adherent and floating cells (Figure 1). Geometrical characteristics, for example, nuclear and cytoplasm thickness, were chosen according to experimental observations (Ottolenghi et al. 1997; Bettega et al. 1998).

In a previous publication (Siragusa et al. 2017), COOLER was validated against full Monte Carlo calculations with the PARticle TRACks (PARTRAC) suite (Friedland et al. 2011), and compared to MIRD standard cellular S-values as well as results based on different track structure calculations using the GEometry ANd Tracking Monte Carlo toolkit version 4 (DNA extension; Geant4-DNA) (http://geant4-dna.org/). However, this is the first time that COOLER was used, tested, and verified under real biological experimental conditions.

\section{Materials and methods}

\section{Cell culture}

Chinese hamster V79 lung fibroblasts were obtained from Dr. Priscilla Cooper (LBNL, Berkeley, CA). V79 cells contain two point mutations in the DNA binding domain of p53 causing the cells to express a mutated non-functional p53 protein (Chaung et al. 1979). Adherent V79 cells were cultured in alpha-Minimum Essential Medium ( $\alpha$-MEM, Sigma-Aldrich, Brøndby, Denmark) supplemented with $10 \%$ fetal bovine serum (FBS, Sigma-Aldrich, St. Louis, MO), $4 \mathrm{mM}$ L-Glutamine (Sigma-Aldrich), 1\% (v/v), and antibiotic/antimycotic solution (working concentration: $100 \mathrm{U} / \mathrm{ml}$ penicillin, $0.1 \mathrm{mg} / \mathrm{ml}$ streptomycin, and $0.25 \mu \mathrm{g} / \mathrm{ml}$ amphotericin B; Sigma-Aldrich). Suspension cultures were grown in Minimum Essential Medium (MEM) Eagle with Joklik modifications for suspension cultures (Sigma-Aldrich) with the same supplement composition. Cell culture flasks (plastic) with ventilation caps (VWR, Søborg, Denmark) were used for adherently growing cells at $37^{\circ} \mathrm{C}, 95 \%$ humidity in $95 \%$ air $/ 5 \% \mathrm{CO}_{2}$ (ESCO Cell Culture $\mathrm{CO}_{2}$ incubator, Holm \& Halby, Brøndby, Denmark), while cells for suspension cultures were transferred to $T 25\left(25 \mathrm{~cm}^{2}\right)$ suspension flasks (Sarstedt, Nuembrecht, Germany) on the day of radiation treatment. Therefore, cells were only in suspension for a short time before exposure (approximately $2 \mathrm{~h}$ ) in addition to the exposure time of maximum $3 \mathrm{~h}$ (highest dose). Suspension cultures treated with HTO were incubated on a rocker (IKA rocker 3D digital, IKA, Staufen, Germany) at the lowest setting of $5 \mathrm{rpm}$ to prevent the cells from settling down on the bottom of the flask. Cells were subcultured after exposure. The cell monolayer was washed once with $1 \mathrm{x}$ Phosphate Buffered Saline (PBS) and trypsinized for about $5 \mathrm{~min}$ at $37^{\circ} \mathrm{C}$ using $0.1 \%$ trypsin (Gibco/Thermo Fisher, Waltham, MA) plus $0.5 \mathrm{mM}$ ethylenediaminetetraacetic acid 


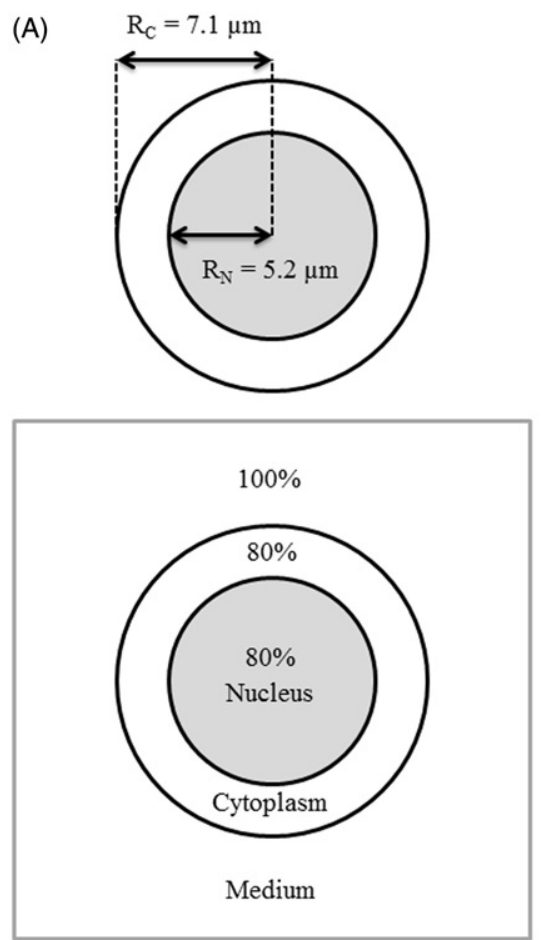

(B)
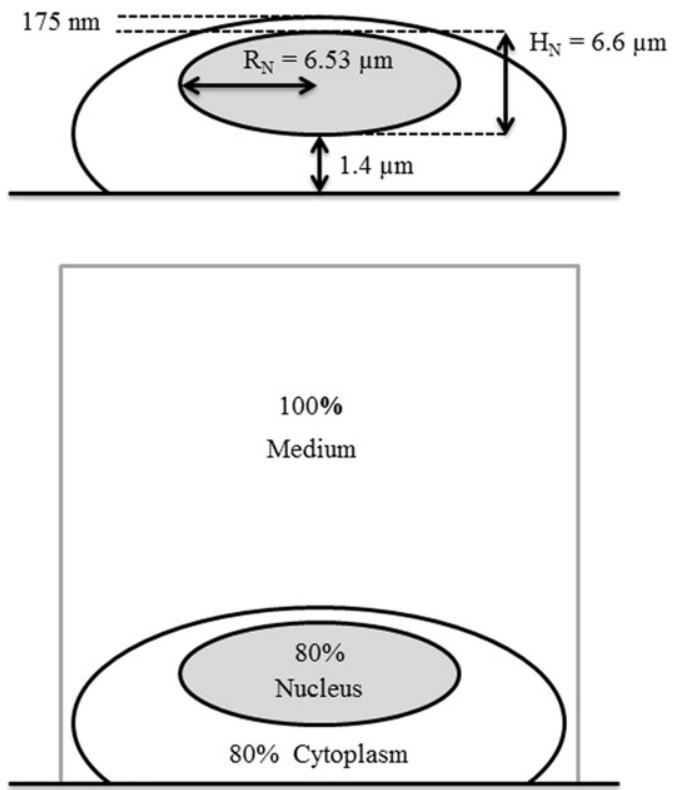

Cell culture flask

Figure 1. V79 cell geometries used for S-value calculations with COOLER (Siragusa et al. 2017). The suspension cell (panel A) is spherical and has a nuclear radius (RN) of $5.2 \mu \mathrm{m}$ and a cellular radius of $7.1 \mu \mathrm{m}$. The adherent cell (panel B) is represented as an ellipsoid with the cytoplasm deformed by attachment to the cell culture flask; the nucleus is considered an ellipsoid with a radius of $6.53 \mu \mathrm{m}$ (two identical semi diameters on the horizontal plane) and a nuclear thickness of $6.6 \mu \mathrm{m}$. The cell and its nucleus appear as concentric disks when seen from above, the thickness of cytoplasm between the bottom of the cell culture flask and the cell nucleus is $1.4 \mu \mathrm{m}$. The height of cytoplasm above the nucleus is fixed at $175 \mathrm{~nm}$. Percentages indicate our assumed water content in the different compartments and therefore an activity reduction factor of 0.8 as compared to the medium concentration (Dewey et al. 1965). HN: height (H) of the nucleus (N); RC: radius (R) of the cell $(\mathrm{C}) ; \mathrm{RN}$ : radius $(\mathrm{R})$ of the nucleus $(\mathrm{N})$.

(EDTA, Sigma-Aldrich, St. Louis, MO) in 1x PBS. Afterwards, cells were plated at appropriate numbers. For all experiments, exponentially growing cells were used to plate samples for radiation exposures.

\section{Irradiation}

\section{Internal radiation exposure with tritiated water}

HTO was purchased from RC Tritec AG (Teufen, Switzerland). It was used to prepare a large volume of stock solution (activity of $19.17 \pm 0.02 \mathrm{GBq} / \mathrm{ml}$ ) in water, which was used for all experiments (the activity dropped from 19.17 to 18.85 $\mathrm{GBq} / \mathrm{ml}$ over the time course of the experiments). The tritium concentration in this stock solution was calibrated by liquid scintillation counting (LSC) and compared to a HTO standard of the National Institute of Standards and Technology (NIST, Gaithersburg, MA, standard reference material 4926E). From the HTO stock solution, amounts of $250 \mu \mathrm{l}$ were added to $5 \mathrm{ml}$ cell culture medium to achieve a nuclear dose rate of $2.4 \mathrm{~Gy} / \mathrm{h}$ (suspension) and $2.2 \mathrm{~Gy} / \mathrm{h}$ (adherent), respectively. For suspension cell cultures, samples of approximately $500 \mu \mathrm{l}$ $\left(0.5 \cdot 10^{6}\right.$ cells) were removed at different times $(10,20,40,60$, 120 , and $180 \mathrm{~min}$ ) from the same flask. Suspension cells were kept on a gentle rocker at $5 \mathrm{rpm}$ during the exposure. For adherent cell cultures independent T25 flasks were set up for each time point and the same amount of HTO was added to each flask. Similar amounts of water were added to the control (non-irradiated) samples.

\section{External radiation exposures with $\gamma$-rays}

The reference exposures were performed in-house at three different dose rates. Acute $(120.8 \mathrm{~Gy} / \mathrm{h})$ and high dose rate (HDR; $3.16 \mathrm{~Gy} / \mathrm{h}$ for adherent and $3.12 \mathrm{~Gy} / \mathrm{h}$ for suspension cells, close to the dose rates used with internal HTO) exposures were performed using a ${ }^{60} \mathrm{Co} \gamma$-ray source $(354 \mathrm{TBq}$ at time of experiment, Terabalt, UJP, Praha). The decrease in dose rate was exclusively achieved by increasing the distance to the ${ }^{60} \mathrm{Co} \gamma$-ray source. No additional shielding material was used to decrease the dose rate. The low dose rate (LDR); $0.34 \mathrm{~Gy} / \mathrm{h}$, adherent cell exposures were performed using a ${ }^{137} \mathrm{Cs} \gamma$-ray source $(5.8 \mathrm{TBq}$ at time of experiment, from a Canberra Nucomat Universal Calibrator System, Canberra, Australia). Dose rates of these sources are calibrated within $\pm 5 \%$ and traceable to the National Institute of Radiation Protection (Statens Institut for Strålebeskyttelse, SIS, Herlev, Denmark). Cells were exposed in flasks with ventilation caps in a small $\mathrm{CO}_{2}$ incubator (compact Midi-40, VWR) except for the acute exposures, which were exposed in flasks with closed caps at room temperature due to the short duration of the exposures (less than $5 \mathrm{~min}$ ). Charged particle equilibrium in the various radiation positions was assured by $5 \mathrm{~mm}$ Polymethyl methacrylate (PMMA) plate in the acute exposure situation, and by the thin incubator door in the LDR and HDR situations. Dose rates of the external exposures were checked against calibrated traceable ion chambers and overall uncertainties in delivered reference doses were less than $5 \%$ absolute. 


\section{Clonogenic cell survival}

Cells were trypsinized and survival curves were plated within the hour after external ( $\gamma$-rays) or internal (HTO) exposure as described here in detail. Adherent cells were trypsinized at $37^{\circ} \mathrm{C}, 5 \% \mathrm{CO}_{2}$ (in an incubator) for $5 \mathrm{~min}$, while suspension cells were washed once with PBS before they were incubated with trypsin in a water bath at $37^{\circ} \mathrm{C}$ for 5 min to break up smaller cell clumps and create a single cell suspension $(0.1 \%$ trypsin with $0.5 \mathrm{mM}$ EDTA in PBS). Afterwards, cells were scored using the count and viability kit for the MUSE compact flow cytometer (Merck Millipore, Darmstadt, Germany). The cell count of viable cells was used for plating cell survival curves with appropriate numbers in T25 flasks with $6 \mathrm{ml}$ complete medium immediately after the exposure. After $7 d$, cells were washed once with $1 \times$ PBS before being fixed and stained with $0.25 \%(\mathrm{w} / \mathrm{v})$ crystal violet in methanol for at least $10 \mathrm{~min}$. Afterwards, cells were washed three times with tap water and air dried before scoring the colonies. Cells that could form a colony of at least 50 cells within the incubation time of $7 \mathrm{~d}$ were considered survivors (Puck and Marcus 1954).

\section{Dosimetry}

Tritiated water (internal exposure) and the use of the COOLER code

HTO diffusion is identical to that of water. Therefore, it is fair to say that HTO can diffuse within minutes throughout the whole cell and the activity is distributed homogeneously during the relatively short exposure times used in our experiments (maximum $3 \mathrm{~h}$ ). The cell water content is assumed to be approximately $80 \%$ in the cell cytoplasm and nucleus (Dewey et al. 1965). Therefore, the nominal activity of HTO within the cytoplasm and nucleus is reduced to 0.8 . No reduction is necessary for the dose received from the medium because a water content of $100 \%$ is assumed (Figure 1).

The concept of S-value has been defined by the (MIRD) committee (Goddu et al. 1997). It represents the absorbed dose to a target region per decay in a source region. In a cellular-dosimetry context, source and target regions are, for instance, the cell nucleus, the cytoplasm, or the entire cell. Svalues are expressed in $\mathrm{Gy} \cdot \mathrm{Bq}^{-1} \mathrm{~s}^{-1}$, equivalent to $\mathrm{Gy}$ per decay. Multiplying the $S$-value by the number of the radioactive decays occurring in the source region within the exposure time, we obtain the absorbed dose (Gy) to the nucleus (the target region).

One of the limitations of the original MIRD formalism is the use of simple spherical cellular models, in which the single cell and its nucleus are modeled as concentric spheres of unit density. However, as cells are often grown as monolayers on plastic surfaces, different geometric configurations are generally required.

In this work, S-values are calculated using a dedicated extension of the recently published COOLER program (Siragusa et al. 2017), which current version includes two cell models, ideally representing V79 fibroblasts grown as attached monolayers or in suspension cultures. COOLER relies on the convolution of two main terms: one related to the position of electron sources (the sites where tritium decays), the other to the density of deposited energy as a function of radial distance from the source. This second term was obtained through full Monte Carlo simulations of electron tracks in liquid water with the code PARTRAC (Friedland et al. 2011).

To test if the cell geometry could have an impact on the S-values and subsequently on the absorbed dose and RBEs, the two different geometry models contained in COOLER were used for suspension and adherent cells. The models are described in Figure 1 and the volumes of all compartments are listed in Table 2.

The importance of the use of the full beta spectrum of tritium on the calculated absorbed dose was investigated through direct comparison of S-values obtained through the use of the entire spectrum or the average beta energy. Information on the decay spectrum and its implementation in COOLER were discussed in (Siragusa et al. 2017).

S-values for the 'Nucleus to Nucleus' $\left(S_{N \leftarrow N}\right)$, 'Cell to Nucleus' $\left(\mathrm{S}_{\mathrm{N} \leftarrow \text { Cell }}\right)$, and 'Total to Nucleus' $\left(\mathrm{S}_{\mathrm{N} \leftarrow \text { Tot }}\right)$ were calculated in COOLER via convolution and used to calculate the

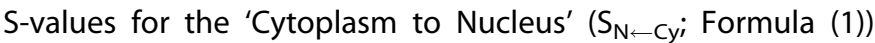
and 'Medium to Nucleus' $\left(\mathrm{S}_{\mathrm{N} \leftarrow \mathrm{M}}\right.$; Formula (2)) cases. In Formulae (1) and (2), $V_{N}, V_{C y}$, and $V_{M}$ are describing the volume $(V)$ of the nucleus $(\mathrm{N})$, cytoplasm (Cy), and medium (M), respectively (terms are defined in caption of Table 2).

$$
\begin{gathered}
S_{N \leftarrow C y}=\frac{S_{N \leftarrow \text { Cell }} \cdot V_{C e l l}-S_{N \leftarrow N} \cdot V_{N}}{V_{C y}} \\
S_{N \leftarrow M}=\frac{S_{N \leftarrow T o t} \cdot V_{T o t}-S_{N \leftarrow N} \cdot V_{N}-S_{N \leftarrow C y} \cdot V_{C y}}{V_{M}}
\end{gathered}
$$

\section{Fitting of clonogenic cell survival curves and RBE-value calculations}

Clonogenic survival was measured in independent experiments $(N=2$ or 3$)$. Triplicate cell samples were used at each dose in each experiment. Using the triplicates, we have calculated average plating efficiencies and standard deviations at different exposure times. Then, surviving fractions and corresponding errors $\left(\sigma_{i}\right)$ have also been calculated for the ith independent experiment. Results of the independent experiments have been pooled together according to standard error propagation techniques. Doseeffect curves were obtained through the weighted least squares fitting technique, using the quantity $1 / \sigma^{2}$ as scaling factor (the weight).

In Figure 2, average surviving fractions $(\overline{S F})$ of $N$ independent experiments are plotted together with error bars that have been calculated as follows:

$$
\sigma_{\overline{S F}}=\frac{1}{N} \sqrt{\sum_{i=1}^{N} \sigma_{i}^{2}}
$$

For the purpose of the fitting and curve analysis, uncertainties of the dose calculations were considered negligible. As for fit function, the linear-quadratic model (Formula 4) 
Table 2. Geometrical parameters and S-values for V79 cells grown in suspension or adherent. The compartment 'Cell' includes the nucleus and the cytoplasm (Cell $=\mathrm{N}+\mathrm{Cy})$, while 'Total' includes all cell compartments and the volume of the cell culture medium (Tot $=$ Cell $+M$ ).

\begin{tabular}{|c|c|c|c|c|}
\hline Compartments & \multicolumn{2}{|c|}{$\begin{array}{l}\text { Suspension } \\
\qquad\left(\mu \mathrm{m}^{3}\right)\end{array}$} & \multicolumn{2}{|c|}{$\begin{array}{c}\text { Adherent } \\
\left(\mu \mathrm{m}^{3}\right)\end{array}$} \\
\hline Volume of the nucleus $\left(V_{N}\right)$ & \multicolumn{2}{|c|}{590} & \multicolumn{2}{|c|}{589} \\
\hline Volume of the cytoplasm $\left(V_{C y}\right)$ & \multicolumn{2}{|c|}{910} & \multicolumn{2}{|c|}{811} \\
\hline Volume of the cell $\left(V_{\text {Cell }}\right)$ & \multicolumn{2}{|c|}{1500} & \multicolumn{2}{|c|}{1400} \\
\hline Volume of cell medium $\left(V_{M}\right)$ & \multicolumn{2}{|c|}{25,500} & \multicolumn{2}{|c|}{25,600} \\
\hline \multirow[t]{2}{*}{ Volume total $\left(V_{\text {Tot }}\right)$} & \multicolumn{2}{|c|}{27,000} & \multicolumn{2}{|c|}{27,000} \\
\hline & \multicolumn{2}{|c|}{ (Gy/decay) } & \multicolumn{2}{|c|}{ (Gy/decay) } \\
\hline$\underline{S \text {-values }}$ & Average & Spectrum & Average & Spectrum \\
\hline S-values: $\mathrm{S}_{\mathrm{N}}$ & $1.46 \mathrm{E}-3$ & $1.36 \mathrm{E}-3$ & $1.44 \mathrm{E}-3$ & $1.34 \mathrm{E}-3$ \\
\hline S-values: $\mathrm{S}_{\mathrm{N}} \leftarrow$ Cell & $6.07 \mathrm{E}-4$ & $6.06 \mathrm{E}-4$ & $6.19 \mathrm{E}-4$ & $5.92 \mathrm{E}-4$ \\
\hline S-values: $\mathrm{S}_{\mathrm{N} \leftarrow \text { Tot }}$ & $3.37 \mathrm{E}-5$ & $3.39 \mathrm{E}-5$ & $3.24 \mathrm{E}-5$ & $3.14 \mathrm{E}-5$ \\
\hline S-values: $S_{N \leftarrow C y}$ & $5.67 \mathrm{E}-5$ & $11.60 \mathrm{E}-5$ & $1.94 \mathrm{E}-5$ & $4.95 \mathrm{E}-5$ \\
\hline S-values: $S_{N \leftarrow M}$ & $0.55 \mathrm{E}-7$ & $2.16 \mathrm{E}-7$ & $2.90 \mathrm{E}-7$ & 7.10E-7 \\
\hline
\end{tabular}

Cy: cytoplasm; M: medium; N: nucleus; Tot: total; V: volume.

was used for the adherent cell branch of the experiment. For suspended cells, the fitting was reduced to the simple exponential function ('the linear model'). The resulting parameters of the curve fit are summarized in Table 3.

RBE calculations were based on the ratio of the doses obtained from calculated fits at $10 \%$ cell survival $\left(D_{10}\right)$. The parameters of the fitting curves are summarized in Table 3.

$$
\text { Surviving Fraction }=\exp -\left(\alpha D+\beta D^{2}\right)
$$

\section{Image acquisition}

Cells were imaged using a Zeiss Axioskop 2 FSmot microscope (Carl Zeiss, Jena, Germany) equipped with a $10 \times / 0.25$ lens (Olympus, Hamburg, Germany). Image acquisition was performed using an AxioCam camera (Zeiss) and the imaging program AxioVision (64bit special edition, Rel. 4.9.1.0 SP1) from Zeiss.

\section{Results}

The data presented here were all collected in rodent V79 cells (fibroblasts). These cells are capable of growing adherent or in suspension by varying the cell culture conditions such as the medium and cell culture flasks.

\section{S-values for different cell geometries}

We have calculated the S-values for V79 cells grown under different cell culture conditions. The cell geometry for suspension and adherent cells is as shown in Figure 1. COOLERcalculated S-values are given in Table 2 together with all the parameters used for their calculation. Considering the two geometrical configurations separately, we mainly observed minor differences in the calculated S-values when comparing calculations based on the single average beta energy to those based on the whole electron energy spectrum. The biggest differences are found in the cytoplasm to nucleus $\left(S_{N \leftarrow C y}\right)$ and medium to nucleus $\left(S_{N \leftarrow M}\right)$ cases. Being in the order of $10^{-7} \mathrm{~Gy} \cdot \mathrm{Bq}^{-1} \mathrm{~s}^{-1}$, the latter always brings a negligible contribution to the absorbed dose.
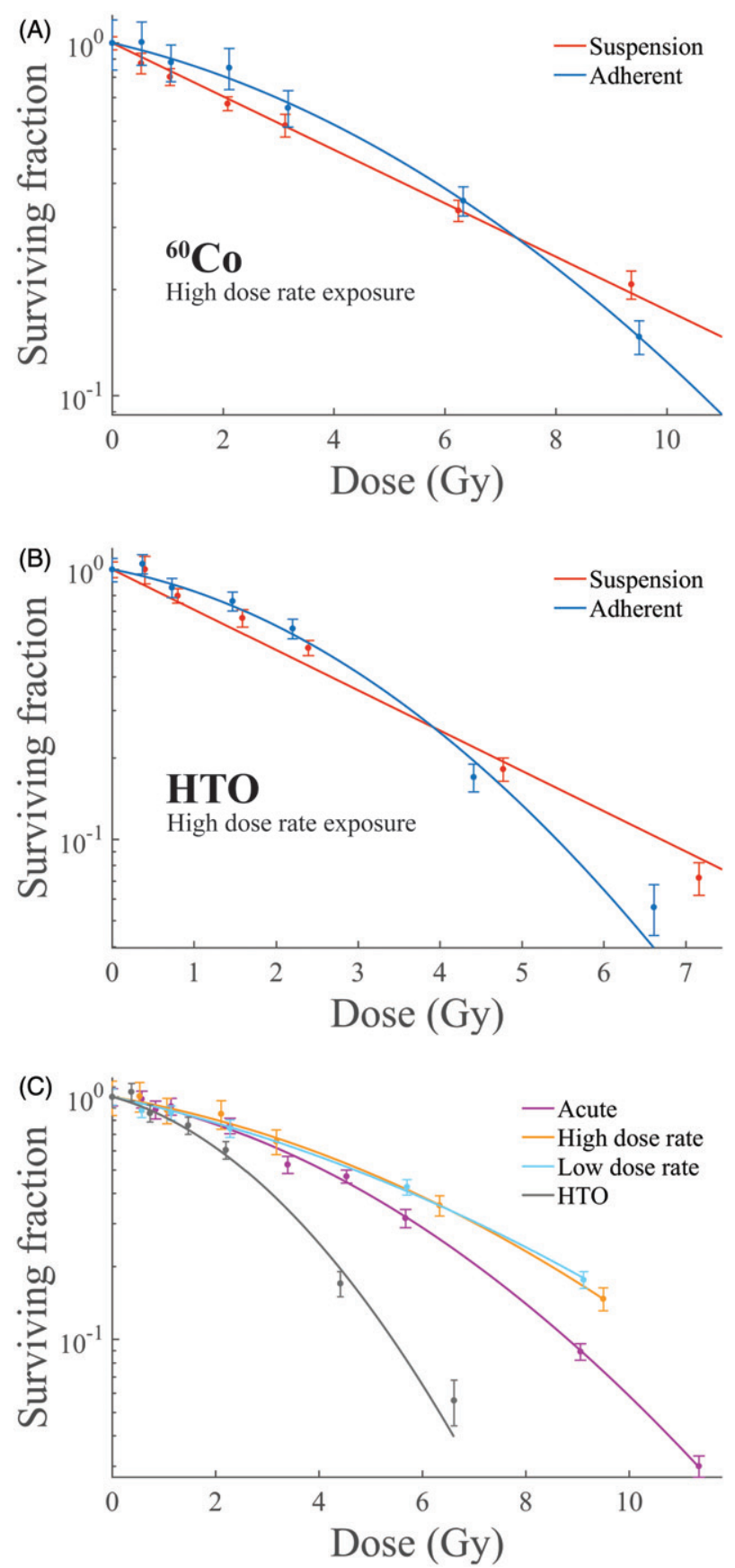

Figure 2. Clonogenic cell survival in V79 cell grown as adherent monolayers (blue line) or in suspension (red line) after exposure to ${ }^{60} \mathrm{Co} \gamma$-rays (panel A) or tritiated water (panel B) at the high dose rates of approximately $3 \mathrm{~Gy} / \mathrm{h}$ (external) or $2 \mathrm{~Gy} / \mathrm{h}$ (internal), as indicated in Table 3. In panel C, dose-effect curves are plotted for clonogenic cell survival in adherent V79 cells after exposure to $\gamma$-rays at different dose rates $(120.8,3.16$, and $0.34 \mathrm{~Gy} / \mathrm{h})$ or tritiated water at a dose rate of $2.2 \mathrm{~Gy} / \mathrm{h}$. In the three panels above, average surviving fractions of two or three independent experiments are plotted together with error bars that have been calculated as in Formula 3.

Generally speaking, the configurations that do not include the nucleus (the target) in the source region show the greatest differences in S-values, irrespective of the geometry and the input energy.

\section{Radiation response for different growth conditions and cell geometries}

V79 cells were cultured as monolayers or in suspension and exposed to external $\gamma$-rays or HTO at different dose rates, as 
Table 3. This table contains a summary of the experimental irradiation settings for different culturing conditions and the parameters of the clonogenic cell survival fit curves, together with the evaluation of the goodness of the fits. RBE calculations were based on the ratio of the doses obtained from calculated fits at $10 \%$ cell survival $\left(D_{10}\right)$. They are presented for each condition and determined using as radiation reference the acute and the high dose rate (HDR) of external ${ }^{60} \mathrm{Co}$-ray exposures.

\begin{tabular}{|c|c|c|c|c|c|c|c|c|c|}
\hline Geometry \& source & Dose rate $(G y / h)$ & $\alpha$ & $\beta$ & SSE & R-square & RMSE & $\mathrm{D}_{10}(\mathrm{~Gy})$ & RBE (acute) & RBE (HDR) \\
\hline Suspension HTO (internal) & $\begin{array}{c}2.40 \\
\text { (high dose rate) }\end{array}$ & 0.34 & - & 11.716 & 0.983 & 1.397 & 6.7 & - & 2.0 \\
\hline Adherent HTO (internal) & $\begin{array}{c}2.20 \\
\text { (high dose rate) }\end{array}$ & 0.13 & 0.05 & 5.619 & 0.989 & 1.06 & 5.4 & 1.6 & 2.0 \\
\hline Suspension ${ }^{60} \mathrm{Co}$ (external) & $\begin{array}{c}3.12 \\
\text { (high dose rate) }\end{array}$ & 0.17 & - & 1.89 & 0.997 & 0.561 & 13.2 & - & 1.0 \\
\hline Adherent ${ }^{60} \mathrm{Co}$ (external) & $\begin{array}{c}3.16 \\
\text { (high dose rate) }\end{array}$ & 0.08 & 0.01 & 0.517 & 0.997 & 0.321 & 10.7 & 0.8 & 1.0 \\
\hline Adherent ${ }^{60} \mathrm{Co}$ (external) & $\begin{array}{l}120.80 \\
\text { (acute) }\end{array}$ & 0.09 & 0.02 & 3.677 & 0.997 & 0.678 & 8.8 & 1.0 & 1.2 \\
\hline Adherent ${ }^{137} \mathrm{Cs}$ (external) & $\begin{array}{c}0.34 \\
\text { (low dose rate) }\end{array}$ & 0.10 & 0.01 & 1.516 & 0.996 & 0.616 & 11.0 & 0.8 & 1.0 \\
\hline
\end{tabular}

SSE: sum of squares due to error; RMSE: root mean squared error.

shown in Table 3. Dose rate and integrated absorbed dose values for the HTO exposures were based on the assumption of only $80 \%$ activity concentration in cell compartments as compared to the medium.

Irrespective of the exposure method, clonogenic cell survival curves for adherent monolayers were always described by linear quadratic fits, while the clonogenic cell survival curves for cells in suspension were fitted using simple exponential functions (Figure 2 and Table 3 ). Cells in suspension always showed higher survival rates (Figure 2(A,B)) at the higher doses (compared to adherent cells).

\section{Dose-rate effects on RBE-values}

In Figure 2(C) dose-effect curves are plotted for clonogenic cell survival of adherent V79 cells after external $\gamma$-ray exposure at different dose rates (acute: $120.8 \mathrm{~Gy} / \mathrm{h}$; HDR: $3.16 \mathrm{~Gy} / \mathrm{h}$; LDR: $0.34 \mathrm{~Gy} / \mathrm{h}$ ) and internal exposure using HTO at a dose rate of $2.2 \mathrm{~Gy} / \mathrm{h}$. The cell survival curves after low and HDR exposures of external $\gamma$-rays are similar. A significant lower survival fraction can be observed for the acute exposure. Survival curves after internal exposure to HTO show the steepest curve and therefore the lowest clonogenic cell survival.

The calculated RBE-values for HTO, which are based on the ratio of the doses obtained from calculated fits at $10 \%$ cell survival $\left(D_{10}\right)$, range from 1.6 to 2.0 for adherent V79 cells, when compared respectively to acute exposures or to similar dose rates of external $\gamma$-rays. A comparison of similar dose rates for suspension cultures also revealed an RBE of 2.0 for clonogenic cell survival at $D_{10}$.

\section{Cell cluster formation in suspension cultures}

In Figure 3, we document the cell cluster formation of V79 cells in suspension. Picture acquisition started when cells were transferred to suspension flasks $(0 \mathrm{~h})$ and up to $5 \mathrm{~h}$, covering the longest exposure time for the highest dose of HTO. Single cells and small cell aggregates containing a couple of cells are visible at time of seeding $(0 \mathrm{~h})$ while larger cell clusters form during the incubation time in suspension.
This large cluster formation happens within a few hours and is due to the cells starting to attach to each other.

\section{Discussion}

This work studies the effects of dose-rate, cell geometry, and employment of tritium whole $\beta$ spectrum rather than its average decay energy on RBE values for HTO in the clonogenic cell survival of $\mathrm{V} 79$ cells. Without a precise and realistic tool for calculation of absorbed dose from the internal tritium activity, it is impossible to achieve trustworthy RBE values. For the first time, we have used the newly developed COOLER code to calculate S-values and the absorbed dose in various sub-cellular compartments (Siragusa et al. 2017). With this tool, it has been possible to handle the non-spherical shape of adherent cells and the asymmetric activity distribution arising from the absence of tritium decays in the plastic of the culture flasks.

In vitro studies of RBE-values are often performed in adherent growing cell monolayers and rarely in suspension cells. The fact that such cells are frequently grown on plastic surfaces might induce an unnatural cell shape that is not representative of an in vivo cell geometry.

The highest S-values are calculated for the nucleus-tonucleus dose deposition $(\mathrm{N} \leftarrow \mathrm{N})$. This was expected due to the fact that beta particles from tritium decays have a relatively short average and maximum range in water of 0.56 or $6 \mu \mathrm{m}$, respectively. Keeping in mind that the cell nuclear radius of our suspension model is $5.2 \mu \mathrm{m}$, most of the energy from a nuclear decay will be deposited in the cell nucleus. Very similar considerations can be made for the adherent cells.

Differences in the $\mathrm{S}$-values can be seen for cytoplasm to nucleus $\left(S_{N \leftarrow C y}\right)$ and medium to nucleus $\left(S_{N \leftarrow M}\right)$ calculations, with a slightly lower S-value for the adherent geometry in comparison with cells in suspension for $\mathrm{S}_{\mathrm{N} \leftarrow \mathrm{cy}}$ and vice versa for $\mathrm{S}_{\mathrm{N} \leftarrow \mathrm{M}}$. In addition, the $\mathrm{S}$-values are higher in these cases when the calculations are based on the whole electron energy spectrum instead of the average electron energy and this is true for both geometries. This can be explained by the fact that if the calculation is based on the average electron energy of $5.7 \mathrm{keV}$, decays occurring further away from the 

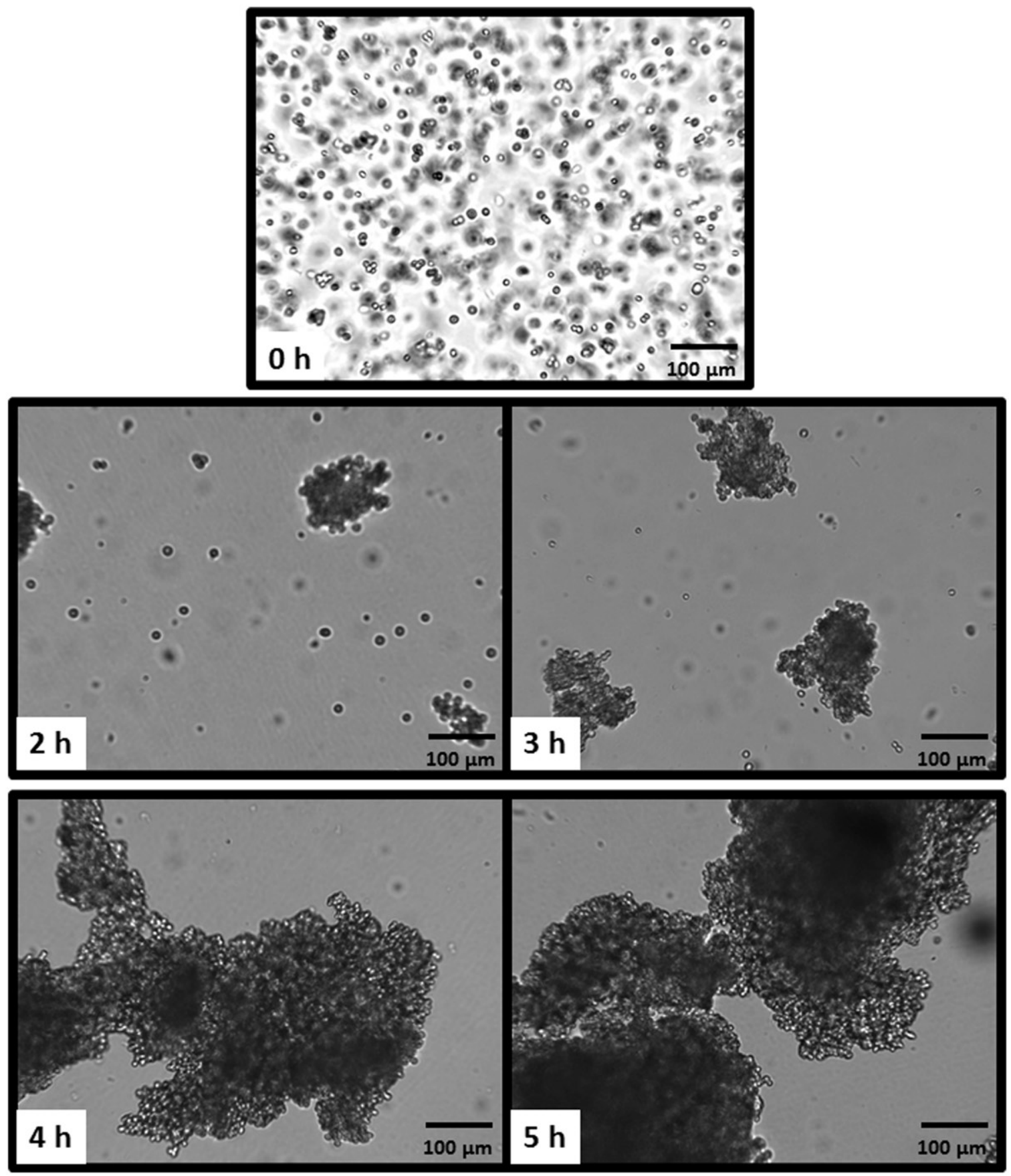

Figure 3. Cell cluster formation during the time V79 cells were in suspension (cell seeding density: $0.5 \times 10^{6}$ cells/ml). Indicated time represents the time of seeding $(0 \mathrm{~h})$ or hours after seeding, respectively $(2 \mathrm{~h}$ until $5 \mathrm{~h}$ ). Tritiated water was added $2 \mathrm{~h}$ after seeding and the highest dose consisted of a $3 \mathrm{~h}$ exposure. The bar in the pictures represents $100 \mu \mathrm{m}$. Imaging was performed using a $10 \times$ objective on a Zeiss microscope and all pictures are presented as seen under the microscope without any enhancement.

nucleus than the average electron range of $0.56 \mu \mathrm{m}$ will not deposit any energy in the nucleus. In contrast, when the calculation is based on the whole electron energy spectrum, all decay closer to the nucleus than the maximum electron range in water of $6 \mu \mathrm{m}$ will be able to deposit energy in the nucleus; and not only those within a distance of $0.56 \mu \mathrm{m}$ from the nucleus. Nevertheless, long-range electrons are emitted by tritium decay with a very low probability and therefore their contribution to the absorbed dose is mostly negligible.

Dose-effect curves from Figure 2(A), obtained after external ${ }^{60} \mathrm{Co} \gamma$-ray exposure for adherent and suspension cultures, present similar characteristics to the clonogenic cell survival curves obtained after internal HTO exposure (Figure 2(B)). In this sense, for the suspension cells, a linear fit described the shape of the dose-effect curve best while for adherent growing cells, a linear-quadratic fit was optimal. Figure 2(A,B) suggest that suspension V79 cells tend to lose reproductive integrity more rapidly than adherent cells at the lower doses, but this aspect is less pronounced after internal exposures. This result supports the assumption that V79 cells are more stressed when grown in suspension than when cultured as adherent monolayers. In the HTO experiments with suspension culture, a gentle flask rocker was used to keep cells 
from settling down on the bottom of the flask. It is known from the literature that V79 cells grown in suspension aggregate more rapidly (already after a few hours) forming small multicellular clusters (Olive 1989). It is also well documented that V79 cells grown only some hours under suspension conditions show an increased radioresistance when compared to monolayers (Dertinger and Hiilser 1981; Olive and Durand 1994; Rasey et al. 1996). In our experimental setup, cluster formation could be observed in suspension cultures within hours (Figure 3) and this could affect the radiation cell response at longer exposure times. In other words, single cells and small clusters were irradiated at the lower doses with short exposure times, but the onset of larger cluster formation might have influenced the results for the higher doses (longer exposures). In principle, this reduces the dose contribution from the surrounding medium to the cell nucleus (contained in $\mathrm{S}_{\mathrm{N} \leftarrow \mathrm{M}}$ ) by $20 \%$ for the cells deep inside the clusters (assuming $80 \%$ water content in the cell). However, this effect is negligible because the nuclear dose contribution is mainly due to the activity contained in the nucleus and cytoplasm of the same cell. This consideration is consistent with the dose-effect curves presented in Figure 2, which show that suspension cultures are more radiation resistant (compared to adherent cultures) at the higher doses (longer exposure times). In this regard, the cell culture condition has been proven to have an effect on the radiation response.

COOLER has been already validated, against full Monte Carlo calculations and compared to MIRD Cellular $S$ value results, but here it is compared to biological results for the first time. The similarities in the dose-response curves for external (measured dose rates) and internal (COOLER-calculated dose rates) exposures are a good biological endpoint verification of the COOLER code calculations and the cell geometry assumptions. In this sense, clonogenic cell survival curves for adherent monolayers were always described by linear quadratic fits, while cells grown in suspension were better represented by simple linear equations (Figure 2).

Our RBE-values were obtained at HDRs for HTO in clonogenic cell survival of V79 cells and compared to external $\gamma$-rays of various dose rates (Figure $2(C)$ ). It is somewhat surprising that the cell survival curves after low and HDR exposures of external $\gamma$-rays are similar. We can hypothesize that the lack of a dose rate effect between the two curves can be due to one. The lack of functional p53 protein in the V79 cells which might make them less prone to dose-rate effects due to diminished cell cycle control or two. A slightly higher RBE of 1.07 for ${ }^{137} \mathrm{Cs}$ compared to ${ }^{60} \mathrm{Co} \gamma$-rays, reported by $\mathrm{Fu}$ et al. (Fu et al. 1979), which could reduce the survival at the LDR. The RBE-values of 2.0 (adherent and suspension cells; similar HDR) or 1.6 (adherent cells; acute $\gamma$-ray exposure) fall well in the range of published RBE-values for HTO (Straume and Carsten 1993; Little and Lambert 2008) with the caveat that most of the studies were performed at lower tritium dose rates and not for clonogenic cell survival. Straume and Carsten showed in their review that the RBEvalues increased with decreasing dose and dose-rate (Straume and Carsten 1993). Therefore, as we used HDRs our
RBE-values should be considered at the lower end of the RBE-value range when it comes to radiation protection.

A proper comparison of HTO RBE-values with different studies is nearly impossible due to the variety of in vitro experimental systems used (different cell types, biological endpoints, dose rates, irradiation setup, and reference radiation). Nevertheless, a methodological similar paper by Ueno et al. report a similar, but slightly lower RBE-value of 1.5 for clonogenic cell survival data at $50 \%$ survival fraction after in vitro exposure of mouse lymphocytic leukemia (L5178Y) cells (Ueno et al. 1982). In the context of our original study aim, any RBE higher than unity is by itself an important result, as it proves the basic proposition that very low energy beta particles deliver their dose with somewhat higher biological impact. This result is also important for the future understanding of biological effects of intracellular Auger cascades.

\section{Conclusions}

In this work, COOLER was employed to test the cell geometry influence and the tritium full beta-decay spectrum (versus the average beta energy) impact on the S-values and, subsequently, on the deposited dose and RBE-values. Combining COOLER with the experimental setup has allowed a more precise dose calculation and, by this, a more accurate RBEvalue calculation.

With the important aid of COOLER, we have obtained carefully controlled sets of clonogenic cell survival curves for V79 cells internally exposed to tritium. We have found that the change in cell culture condition growth must be taken into account (single spherical cell, suspended cell clusters, and adherent cells). After comparison to S-values calculated for different cell geometries, no substantial difference was found between the use of the whole beta decay spectrum and its average decay energy. Finally, our findings underline the importance of using internal radiation and reference radiation at the same dose rate and stating the dose rate when measuring in vitro RBE-values.

Our measurements give us RBE values of 1.6-2.0 for HTO evenly distributed in the cell. Our experimental design excludes the long-term effect of direct tritium incorporation in the DNA, and the higher than unity RBE value found can therefore only be attributed to the disproportionate high contribution of higher LET end-of-track events of low energy electrons to the biological effect.

Finally, we believe that our experimental design and methodological measures create a new standard for performing radiobiological studies with HTO.

\section{Acknowledgments}

The V79 cells were obtained from Dr. Priscilla Cooper (LBNL, Berkeley, CA) as a generous gift. We thank Arne Miller for providing access and training for the radiation facility. Special thanks are given to Claus Andersen for training and providing the external dosimetry and to Sofia Barbieri for the precious advice on the statistics of clonogenic cell survivals. Further, we would like to thank the members of The Hevesy Laboratory for their support and give special thanks to all the laboratory technicians. The research was financed by The Hevesy Laboratory. 


\section{Disclosure statement}

The authors report no conflicts of interest. The authors alone are responsible for the content and writing of the manuscript.

\section{Notes on contributors}

Mattia Siragusa is a $\mathrm{PhD}$ candidate at the Technical University of Denmark (DTU). He is involved in cellular dosimetry calculations for low energy electrons and in the development of computer-vision-based automated cell colony counters.

Pil M. Fredericia is a PhD candidate at the Technical University of Denmark (DTU). She is investigating the radiotoxicity and biological response of low energy electrons with a special focus on Auger electron emitters.

Mikael Jensen is an experimental nuclear physicist, isotope producer, radiochemist and medical physicist. He is a professor of applied nuclear physics at DTU.

Torsten Groesser is a researcher at the Technical University of Denmark (DTU). He is a biophysicist with experience in performing ionizing radiation experiments using low- and high-LET radiation including radioisotopes to study in vitro radiation responses.

\section{References}

Bettega D, Calzolari P, Doglia SM, Dulio B, Tallone L, Villa AM. 1998. Technical report: cell thickness measurements by confocal fluorescence microscopy on $\mathrm{C} 3 \mathrm{H} 10 \mathrm{~T} 1 / 2$ and V79 cells. Int J Radiat Biol. 74:397-403.

Carsten AL. 1979. Tritium in the environment: isotopic effects and transmutations. Adv Radiat Biol. 8:419-459.

Chaung W, Mi L, Boorstein RJ. 1979. The p53 status of Chinese hamster V79 cells frequently used for studies on DNA damage and DNA repair. Nucleic Acids Res. 25:992-994.

Dertinger HI, Hiilser D. 1981. Increased radioresistance of cells in cultured muiticell spheroids. I. dependence on cellular interaction. Radiat Environ Biophys. 19:101-107.

Dewey WC, Humphrey RM, Jones BA. 1965. Comparisons of tritiated thymidine, tritiated water, and cobalt- 60 gamma rays in inducing chromosomal aberrations. Radiat Res. 24:214-238.

Diabaté S, Strack S. 1993. Organically bound tritium. Health Phys. 65:698-712.

Friedland W, Dingfelder M, Kundrát P, Jacob P. 2011. Track structures, DNA targets and radiation effects in the biophysical Monte Carlo simulation code PARTRAC. Mutat Res Fundam Mol Mech Mutagen. 711:28-40.

Fu KK, Phillips TL, Heilbron DC, Ross G, Kane LJ. 1979. Relative biological effectiveness of low- and high-LET radiotherapy beams for jejunal crypt cell survival at low doses per fraction. Radiology. 132:205-209.

Goddu SM, Howell RW, Bouchet LG, Bolch WE, Rao DV. 1997. Mird cellular $S$ values. Reston, VA: Society of Nuclear Medicine.
Goodhead D. 2002. Committee examining radiation risks of internal emitters (CERRIE). J Radiol Prot. (Lond.). 22:1-162.

Hall EJ, Oliver R, Bedford JS. 1967. The relative biological effectiveness of tritium beta particles compared to gamma radiation-its dependence on dose-rate. Br J Radiol. 40:704-710.

Harrison JD, Khursheed A, Lambert BE. 2002. Uncertainties in dose coefficients for intakes of tritiated water and organically bound forms of tritium by members of the public. Radiat Prot Dosimetry. 98:299-311.

Kassis Al. 2004. The amazing world of Auger electrons. Int J Radiat Biol. 80:789-803.

Le Guen B. 2009. Impact of tritium around EDF nuclear power plants. J Radiol Prot. 29:163-173.

Little MP, Lambert BE. 2008. Systematic review of experimental studies on the relative biological effectiveness of tritium. Radiat Environ Biophys. 47:71-93.

Little MP, Wakeford R. 2008. Systematic review of epidemiological studies of exposure to tritium. J Radiol Prot. 28:9-32.

Lucas LL, Unterweger MP. 2000. Comprehensive review and critical evaluation of the half-life of tritium. J Res Natl Inst Standards Technol. 105:541-549.

NCRP Report. 1979. National Council on Radiation Protection and Measurements (U.S.) report No. 63. 1979. Tritium and other radionuclide labeled organic compounds incorporated in genetic material: recommendations of the National Council on Radiation Protection and Measurements. Washington, D.C.: NCRP.

Olive PL, Durand RE. 1994. Drug and radiation resistance in spheroids: cell contact and kinetics. Cancer Metastasis Rev. 13:121-138.

Olive PL. 1989. Cell proliferation as a requirement for development of the contact effect in Chinese hamster V79 spheroids. Radiat Res. 117:79-92.

Ottolenghi A, Monforti F, Merzagora M. 1997. A Monte Carlo calculation of cell inactivation by light ions. Int J Radiat Biol. 72:505-513.

Pinson EA, Langham WH. 1957. Physiology and toxicology of tritium in man. J Appl Physiol. 10:108-126.

Puck BYTT, Marcus PI. 1954. A rapid method for viable cell titration and clone production with HeLa cells in tissue culture: the use of X-irradiated cells to supply conditioning factors. Proc Natl Acad Sci USA. 41:433-437.

Rasey JS, Cornwell MM, Maurer BJ, Boyles DJ, Hofstrand P, Chin L, Cerveny C. 1996. Growth and radiation response of cells grown in macroporous gelatin microcarriers (CultiSpher-GTM). $\mathrm{Br} J$ Cancer Suppl. 74:78-81.

Siragusa M, Baiocco G, Fredericia PM, Friedland W, Groesser T, Ottolenghi A, Jensen M. 2017. The COOLER code: a novel analytical approach to calculate sub-cellular energy deposition by internal electron emitters. Radiat Res. 188:204-220.

Straume T, Carsten AL. 1993. Tritium radiobiology and relative biological effectiveness. Health Phys. 65:657-672.

Ueno AM, Furuno-Fukushi I, Matsudaira H. 1982. Induction of cell killing, micronuclei, and mutation to 6-thioguanine resistance after exposure to low-dose-rate gamma rays and tritiated water in cultured mammalian cells (L5178Y). Radiat Res. 91:447-456.

Vri RM-D, Binet J. 1984. Molecular aspects of tritiated water and natural water in radiation biology. Prog Biophys Mol Biol. 43:161-193. 